\title{
Integrating Second Life into an EFL Program: Students' Perspectives
}

\author{
Charles Xiaoxue Wang \\ Georgia State University, USA \\ Hongbo Song \\ Fangli Xia \\ Qiaoqiao Yan \\ Yantai University, P. R. China
}

\begin{abstract}
Second Life (SL) is a three dimension virtual world imagined and created by its users. To explore various facets of language learning within SL, faculty members of an American university and a Chinese university took an evaluation research approach to search for appropriate ways to integrate SL into an EFL (English as a Foreign Language) program. This paper reports a part of the research efforts with a focus on the Chinese students' perspectives of an EFL Program in SL. Specifically included in this paper are (a) the Chinese students' perceived technology readiness to use SL for EFL learning, (b) their perceptions of SL, and (c) the EFL Program implemented in $S L$. The paper reviews related literature and theoretical support, describes the study's context and its implementation procedures, and discusses the evaluation results and implications. Finally, the paper shares with the audience some considerations for integrating SL into an EFL program.
\end{abstract}

Keywords: Language learning, Second Life, Multi-user virtual environment, Technology integration, Student perceptions.

\section{Introduction}

Recently, educational researchers and practitioners alike have paid considerable attention to the use of multi-user virtual environments (MUVEs) to support learning across curricula, "Educational MUVEs have emerged in recent years as a form of socioconstructivist and situated cognition-based educational software" (Nelson \& Ketelhut, 2007, p. 269). Among those MUVEs created through various media, Second Life (SL) is one of the most popular. As of May 2008, there were over 18 million registered user accounts
(Second Life Economic Statistics, May 2008). SL is largely adopted for academic, social, and business purposes and many educational institutions have begun to explore Second Life as a platform for education (Lamb, 2006). By March 2007, over 200 universities or academic institutes were already involved in SL (Kelton, 2007).

This paper reports on a recent research collaboration endeavor between faculty members of an American university and a Chinese university to explore various facets of English as a Foreign Language (EFL) learning 
within SL. The ultimate purpose of this research collaboration is to find appropriate ways to integrate SL into an EFL program in China.

The exploration and research in this project are informed by social constructivist principles as applied to EFL learning. The approach to investigate related issues and problems for practical solutions is evaluation research (Krathwohl, 1998; McMillan \& Schumacher, 1997). Our efforts to this point have been to explore (a) how the affordances of SL might be a useful tool that can mediate EFL learning, (b) the effects of the EFL Program in SL on Chinese students' oral proficiency, (c) the Chinese students' perceived technology readiness for using SL, and (d) the Chinese students' perceptions of SL and the EFL Program implemented in SL. This paper reports on the Chinese students' perceived technology readiness for using SL, and the Chinese students' perceptions of SL and the EFL Program implemented in SL.

\section{Literature Review}

There is an emerging discussion about MUVEs as tools for second and foreign language instruction (e.g., Cooke-Plagwitz, 2008). This phenomenon has likely emerged from a combination of research on Computer Assisted Language Learning (CALL) and Computer Mediated Communication (CMC). Digitallymediated literacy practices (e.g., list-servs, blogs, online chatting, email correspondence, online postings) and social-networking practices, mediated by such tools as Facebook, MySpace, and Xanga, can provide language learners with meaningful opportunities to engage in multiple literacy practices and to construct learner identities through interactive activities in virtual communities (Black, 2005; Lam, 2000; Yi, 2008).

A primary focus of CALL and CMC research has been on the use of technologies for the development of literacy in a second or foreign language (Lam, 2000; Shei, 2005). Yet, little is known about how emerging technologies, and MUVEs in particular, influence the ways in which language learners improve their language proficiency. In addition, despite the great potential of this emerging technology to augment language instruction, very little research has been conducted on the use of any form of MUVEs in the context of learning English as a Foreign Language (EFL) - where English is not spoken in everyday life, but is often limited to the classroom (e.g., learning English in China).

We chose to explore one of the largest and most well-known MUVEs, Second Life (SL) (http://secondlife.com). SL, as a medium, provides an array of rich environments for learning and instruction. In terms of language learning, SL can provide a friendly, appealing, and contextually relevant space for native speakers of a target language to interact with language learners. This affords the language learners opportunities to interact with native speakers in realistic, authentic, and relevant settings such as offices, shops, athletic events, business meetings, and classrooms. SL also offers access to up-to-date online instructional resources in a variety of media formats (e.g., video, photographs, documents, interactive lessons, simulated gaming).

In SL, learners communicate through text messages, audio conversations, and their avatar's non-verbal gestures (e.g., waving, thumbs-up). An avatar is a SL user's 3D graphic representation through which the SL user interacts with other people in SL. SL also offers capabilities to record events taking place within SL. This allows language learners to review and reflect on their personal performance and interactions with others by watching their own recorded video clips in SL. The recording also provides instructors and researchers with 
a second chance to analyze their students' performance both from the linguistic and social communication perspectives. In China, scholars in the field are anxious to discover a supportive and constructive language learning environment for EFL learners. Li and Mao (2008) find that SL can enhance social learning and enhance interactions from three dimensions: (1) learner to learner, (2) learner to object, and (3) object to object.

In early 2007, SL introduced voice over internet protocol (VoIP) into its architecture. Prior to the introduction of VoIP, most conversations in SL were conducted through text chat (Au, 2008). VoIP has allowed users to communicate verbally in real-time, adding a layer of authenticity to the text-based interaction. Equally important is the fact that online text-based interactions (e.g., written forms of discourse) have been shown to have significant relationships or overlaps with oral discourse (Belcher \& Hirvela, 2008). Moreover, one form of discourse could help language learners acquire the other form. In other words, second language learners' textbased interactions within SL are likely to help them improve their spoken discourse. Given the features of SL noted above (i.e., realistic, authentic, and relevant settings, VoIP, and the relationship between oral and written discourse), SL presents a unique opportunity to practice speaking in a target language, particularly for learners who have a very limited opportunity to hear, use, and practice English in real-world and/or off-line contexts.

\section{Research Questions and Methodology}

The purpose of the research collaboration is to find appropriate ways to integrate SL into an EFL program in Chinese universities. This paper reports the Chinese students' perceived technology readiness for using SL and the Chinese students' perceptions of SL as a language learning platform and the EFL
Program implemented in SL.

\section{1. Research Questions}

The related research questions include:

- Are the Chinese students ready to use $\mathrm{SL}$ as a language learning platform in terms of technology skills?

- What are the Chinese students' perceptions of SL as a language learning platform?

- What are the Chinese students' perceptions of the EFL Program in SL?

\section{2. Research Methodology}

The study took an evaluation research approach (Krathwohl, 1998; McMillan \& Schumacher, 1997) to explore the related issues of integrating SL into an EFL program in China. Evaluation research, like action research, is under the umbrella of a practitioner inquiry model (Cochran-Smith \& Donnell, 2006). However, the purposes of evaluation research differentiate this form from other research approaches. According to Krathwohl (1998) and McMillan and Schumacher (1997), evaluation research has a number of unique characteristics.

- Evaluation research is decision-driven instead of hypothesis-driven.

- The value of evaluation research is in its utilization.

- Because evaluation research is decision-driven, it takes a holistic approach, which sees education as a complex human endeavor.

- Evaluation does not control and manipulate the variables existing in actual evaluation situations.

- Evaluation research uses a multiplicity of data from different sources combining qualitative and quantitative data. 
This study took the evaluation research approach for three major reasons. First, evaluation research fits the researchers' epistemological beliefs of social cognitive learning that advocates learning through interaction and collaboration in social contexts (Driscoll, 2000). Second, to find out effective and practical ways to integrate SL into an EFL program, the implementation of the pilot EFL Program in SL must be carried out in the real context in which the final EFL Program is expected to function. Third, the research context makes using other research approaches unrealistic in that the need to control and manipulate certain variables is clear.

\section{3. Research Context and Participants}

The study was implemented online in SL with participants from both a state university in the USA and a major provincial university in Eastern China. The American university is the Southeast's leading urban research institution in the USA. The Chinese university is a comprehensive university with twenty academic schools and departments. The participants from the American university were 20 undergraduate students taking a course on IT 2010: Computer Skills for the Information Age. Their participation in the study was part of their course work requirements. The study participants from the Chinese university were 61 full time sophomores majoring in English in the School of Foreign Languages. They were the target students of the research program (and we use $N$ to represent them in the report).

Among the 61 study participants, 20 were selected to participate in the EFL Program in SL, including 7 male students (35\%) and 13 female students (65\%) (and we use $n$ to represent them in the report). Their ages ranged from 19 to 23 years with an average of 21. The participants were selected on a voluntary basis and based on their comprehensive evaluation scores of the previous academic semester (Fall 2008). Due to practical constraints that did not allow random sampling for the EFL Program in SL, we purposively selected the participants based on their comprehensive evaluation scores to ensure that they best represented the target students academically. The comprehensive evaluation consisted of the evaluation on students' listening comprehension, speaking proficiency, and reading and writing abilities. The evaluation was done by professors at the university on a semester basis. Table 1 summarizes the comprehensive evaluation scores of the target students and the selected participants for the EFL Program in SL.

Table 1. The Summary of the Comprehensive Evaluation by Scores Range

\begin{tabular}{ccccc}
\hline \multirow{2}{*}{$\begin{array}{c}\text { Score Range } \\
\text { Max =100) }\end{array}$} & \multicolumn{2}{c}{ Target Students $(N=61)$} & \multicolumn{2}{c}{ The EFL Program Participants $(n=20)$} \\
\cline { 2 - 5 } & Student Number & Score Average & Participant Number & Score Average \\
\hline $90-100$ & 7 & 91.31 & 3 & 91.88 \\
$80-89$ & 42 & 85.67 & 14 & 85.58 \\
$70-79$ & 10 & 77.65 & 3 & 77.83 \\
$60-69$ & 2 & 68 & 0 & 0 \\
Under 60* & 0 & 0 & 0 & 0 \\
\hline *Any score under 60 is regarded as a failure for the evaluation. \\
\hline \multicolumn{7}{l}{}
\end{tabular}




\section{4. Learning Tasks and Procedures}

The EFL Program in SL lasted for five weeks from March 24 to April 26, 2009. The program provided the participants with the opportunities to interact with American students synchronously online in SL. The learning tasks for each week were (a) one hour of learning activities in SL, (b) blog writing on the learning experiences in SL, and (c) language preparation for learning activities in SL for the next week. The learning activities in SL included a SL workshop in a lecture format, virtual tours in groups and one-on-one with SL partners, small group discussions, a one-on- one interview with the American partners, and individual presentations. A Web site was created to give detailed instruction on how to complete the tasks for each week. Following the given instructions on the Web site, the participants completed their tasks at an Internet Center on the Chinese university campus. Two Chinese research assistants were present at the site to provide necessary technical support. Figure 1 shows the screenshots of the participants completing different learning tasks in SL and Table 2 summarizes the tasks for the EFL Program participants at the Chinese university.

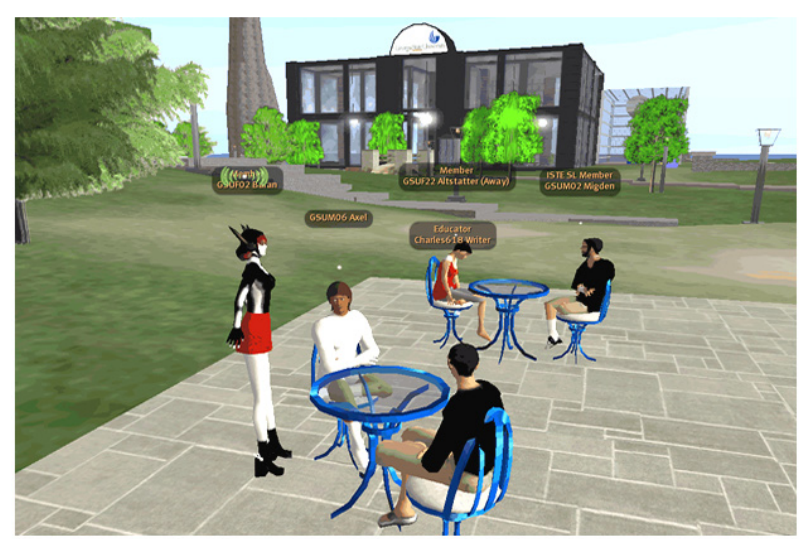

One-on-one Interview

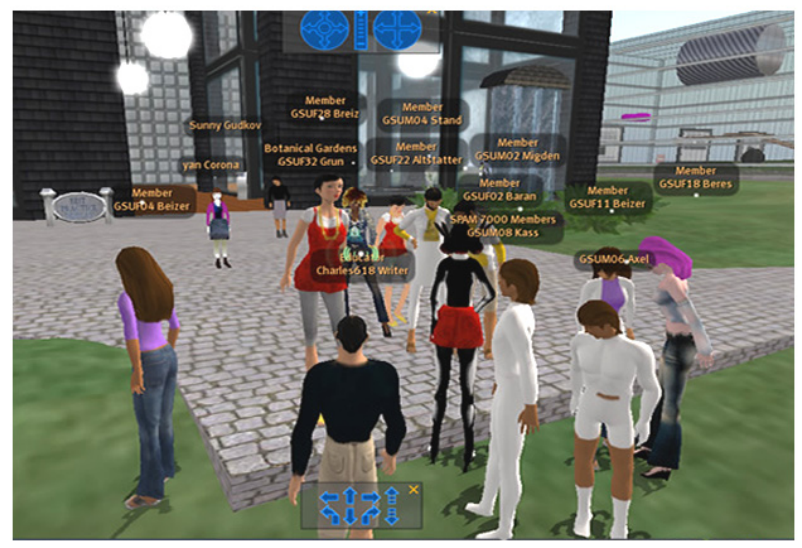

Virtual Tour

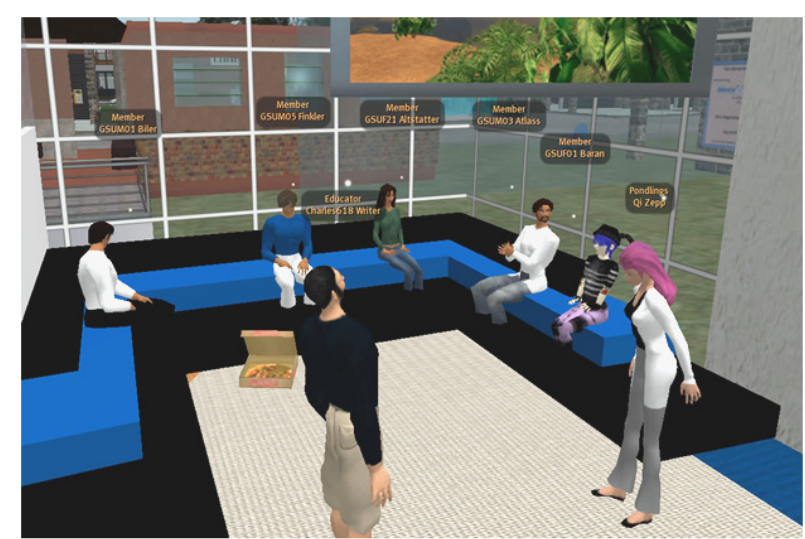

Group Discussion

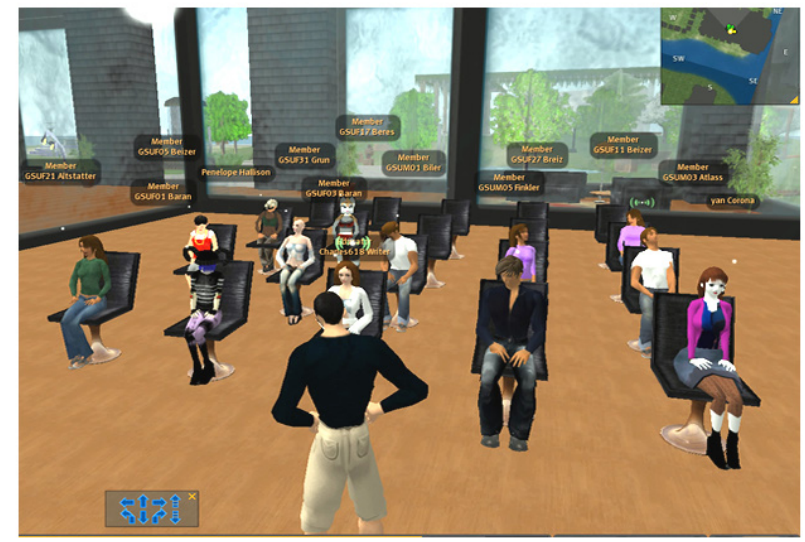

Presentation

Figure 1. Different Learning Tasks in SL 
Table 2. Dates and Task Contents of the Research Program in SL

\begin{tabular}{|c|c|c|}
\hline Dates & Task Contents & Notes \\
\hline $\begin{array}{l}\text { Week 1: } \\
\text { March 24-29 }\end{array}$ & $\begin{array}{l}\text { 1. Conduct Second Life Workshop. } \\
\text { 2. Take a virtual tour (visiting Capitol Hill and Princeton } \\
\text { University Campus in SL). } \\
\text { 3. Write a report in English about your virtual tour and post it } \\
\text { on the blog. } \\
\text { 4. Prepare for the next week. }\end{array}$ & $\begin{array}{l}\text { SL activities } \\
\text { were in } \\
\text { groups with } \\
\text { researchers. }\end{array}$ \\
\hline $\begin{array}{l}\text { Week 2: } \\
\text { March 30- } \\
\text { April } 5\end{array}$ & $\begin{array}{l}\text { 1. Meet and talk with the American students about university } \\
\text { student life. } \\
\text { 2. Write a report in English about your conversation with an } \\
\text { American student and post it on the blog. } \\
\text { 3. Prepare for the next week. }\end{array}$ & $\begin{array}{l}\text { One-on- } \\
\text { one with } \\
\text { American } \\
\text { students. }\end{array}$ \\
\hline $\begin{array}{l}\text { Week 3: } \\
\text { April 6-12 }\end{array}$ & $\begin{array}{l}\text { 1. Meet and discuss with the American students about ideal } \\
\text { jobs and how you would prepare for ideal jobs. } \\
\text { 2. Write a report in English about your discussion and post it } \\
\text { on the blog. } \\
\text { 3. Prepare for the next week. }\end{array}$ & $\begin{array}{l}\text { Group } \\
\text { activity with } \\
\text { American } \\
\text { students. }\end{array}$ \\
\hline $\begin{array}{l}\text { Week 4: } \\
\text { April 13-19 }\end{array}$ & $\begin{array}{l}\text { 1. Interview an American student on technology uses for } \\
\text { learning and for fun. } \\
\text { 2. Write a report in English about your interview and post it } \\
\text { on the blog. } \\
\text { 3. Prepare for the next week. }\end{array}$ & $\begin{array}{l}\text { One-on- } \\
\text { one with } \\
\text { American } \\
\text { students. }\end{array}$ \\
\hline $\begin{array}{l}\text { Week 5: } \\
\text { April 20-26 }\end{array}$ & $\begin{array}{l}\text { 1. Select one of the following three topics and present it in } \\
\text { English in SL: } \\
\text { - American students' perspective on an ideal job and } \\
\text { how he/she prepares for it. } \\
\text { - Using technologies for learning and for fun: An } \\
\text { American student's perspective. } \\
\text { - My experience of communicating with American } \\
\text { students in SL. } \\
\text { 2. Write a report in English about your interview and post it } \\
\text { on the blog. }\end{array}$ & $\begin{array}{l}\text { SL activities } \\
\text { were in } \\
\text { groups with } \\
\text { American } \\
\text { students. }\end{array}$ \\
\hline
\end{tabular}




\subsection{Data Collection and Data Analysis}

This study used both qualitative and quantitative analysis (Creswell, 2008). Data collection methods included (a) pre-program and post-program surveys, (b) interviews, and (c) documentation reviews (e.g., blog posting). The pre-program survey captured the Chinese students' technology readiness for using SL as a language learning platform and the postprogram survey targeted their perceptions of SL and the EFL Program in SL. Two professors in the USA and one in China reviewed both the pre-program and post-program surveys. These professors were experts in both survey content and survey format. Additionally, two students at Chinese university were also invited to review the surveys to ensure that the language level were appropriate for the target users. Because the survey's purpose was to solicit opinions of students towards the research targets, descriptive statistics were used to analyze the data collected from the surveys in order to describe students' technological readiness for using SL for EFL learning, their perceptions of SL, and the EFL Program in SL.

Three sets of interviews were completed at the beginning of, in the middle of, and after the research program. Each set of interviews consisted of five to seven one-on-one interviews and a focus group interview comprised of three to four participants. The interviews were semistructured interviews conducted face-to-face with the Chinese participants at the Chinese university. All the interviews were conducted in Chinese to ensure that the EFL Program participants could fully express their opinions and describe their feelings. The average length of the one-on-one interviews was about thirteen minutes and the average length of the focus group interviews was a little over fifteen minutes. The interviews were recorded and transcribed for analysis. To triangulate the findings, the research team also reviewed the
Chinese students' weekly blog postings on the ten blog sites at eblogger.com. Both the interview transcripts and blog postings were categorized, coded, and analyzed by the research members from both China and the USA.

\section{Results}

The research findings presented below correspond with the research questions above. Specifically, the findings describe the Chinese students' perceived technology readiness for using SL as a language learning platform and their perceptions of SL and the EFL Program implemented in SL.

\subsection{Perceived Technology Readiness for}

\section{Using $S L$}

A pre-program survey was designed to depict the Chinese students' perceived technology readiness for using SL. The survey consisted of twenty statements on a five-point Likert scale questionnaire. The survey required the participants to rate confidence of performing technology related tasks in three categories: (1) computer operation, (2) online activities, and (3) digital technology. In the survey, five items centered upon computer operation such as "I know how to move a file to a new location on a computer" and "I know how to use a program to clean my computer when it was affected by a virus." Twelve items focused on their on-line experiences ranging from "online discussion as a course work" to "online gaming" and "online shopping." Three survey items were about other experiences with digital technology such as cell phones, digital cameras, and video cameras. The pre-program survey was completed prior to the EFL Program in SL. Of the 61 study participants at the Chinese university, 57 completed the pre-program survey. The data analysis coded "Strongly Disagree" as 1 and "Strongly Agree" as 5. Table 3 summarizes the pre-program survey results in categories. 
Table 3. Summary of the Pre-program Survey Results

\begin{tabular}{lccc}
\hline \multicolumn{1}{l}{ Participants at the Chinese University $(N=57)$} & & \\
\hline \multicolumn{1}{c}{ Survey Categories } & No. of Survey Items & Mean & $S D$ \\
\hline Computer Operation & 5 & 4.34 & .67 \\
Online Activities & 12 & 3.30 & 1.23 \\
Digital Technology & 3 & 4.23 & .80 \\
\hline Overall & 20 & 3.96 & .90
\end{tabular}

Table 3 indicated that Chinese participants were ready to perform computer operation tasks and they were all experienced in using cell phones, digital cameras, and video cameras. With a mean of 3.30 from a maximum value of 5 for online activities, a standard deviation of 1.23 pointed out a relatively large variance in this category. Further analysis revealed that the Chinese participants rated some online activities higher than others in the survey category of online activities. The Chinese participants were experienced in using online communication tools (e.g., QQ, PoPo, MSN Messenger, Skype) for online chatting (survey item 15) and many of them had their own online photo albums such as Facebook, QQ Zone, and Xiaonei.com (survey item 12). However, for the online discussions (survey item 14 , Mean $=2.75, S D=1.41$ ) and for playing online virtual games (survey item 19, Mean $=2.93, S D=1.51$ ), the survey results indicate that the Chinese students were not as experienced as in using online communication tools for chatting (survey item 15). Again, further analysis revealed variances among the students, which indicated that a small group of Chinese students were experienced in online discussions for their course work and that they did play online virtual games while the majority did not. For those who did play online virtual games, the amount of time they spent on playing them was low (survey item 20, Mean = $1.86, S D=1.16$ ). To answer the first research question, the Chinese students were ready to use SL for EFL learning. Table 4 on the next page summarizes some online activities that were closely related to those learning tasks in the EFL Program in SL.

\subsection{SL as a Language Learning Platform}

The EFL Program participants' perceptions of SL as a language learning platform were revealed through a post-program survey, interviews, and blog postings. The post-program survey was designed to collect information on the EFL Program participants' perceptions of both SL as a language learning platform and the EFL research program itself. The survey consisted of twenty-three statements on a five-point Likert scale questionnaire with an opportunity for the participants to write any additional thoughts and opinions. Out of 23 survey items, 10 were about the EFL Program participants' perception of SL as a language learning platform. The questions required the program participants to rate their feelings towards given statements about SL regarding its interface, avatar, actions, communication, and general feelings about SL. 
Table 4. The EFL Program Related Online Activities

\begin{tabular}{clcc}
\hline Survey Item & \multicolumn{1}{c}{ Statements } & Mean & $S D$ \\
\hline 12 & $\begin{array}{l}\text { I have my own online photo album, such as Facebook, } \\
\text { QQ zone and xiaonei.com. }\end{array}$ & 4.79 & .73 \\
15 & $\begin{array}{l}\text { I have used online audio and video communication } \\
\text { tools such as QQ, MSN Messenger, Yahoo Messenger, }\end{array}$ & 4.75 & .58 \\
& PoPo, Skype, and etc. to chat with people. & & \\
14 & $\quad \begin{array}{l}\text { I have participated online discussions in my course } \\
\text { study. }\end{array}$ & 2.75 & 1.41 \\
19 & I have played online virtual games. & 2.93 & 1.51 \\
20 & I usually play virtual games for at least 3-5 hours a & 1.86 & 1.16 \\
& week.
\end{tabular}

Generally speaking, the post-program survey showed that the EFL Program participants had positive feelings towards SL as a language learning platform (Mean $=4.38$, $S D=.64)$. They felt that it was easy to control their avatars and easy to navigate around in the
SL environment. They all liked the interface and virtual environments of SL and felt interested to communicate with others in SL. Table 5 summarizes the post-survey results by statement categories.

Table 5. Summary of the Post-program Survey Results on SL

EFL Program participants at the Chinese University $(n=20)$

\begin{tabular}{lccc}
\hline \multicolumn{1}{c}{ Survey Categories } & No. of Survey Items & Mean & $S D$ \\
\hline Interface & 2 & 4.33 & .79 \\
Avatar & 2 & 4.00 & .86 \\
Actions & 2 & 4.25 & .59 \\
Communications & 2 & 4.58 & .62 \\
General Feelings & 2 & 4.73 & .34 \\
\hline Overall & 10 & 4.38 & .64 \\
\hline
\end{tabular}

Positive feelings toward SL as a language learning platform were also clearly indicated in the interviews. The following comments from the participants echoed and supported the findings in the post-program survey.

Interface: I feel that the whole interface is interesting and fresh. We can go to different locations to talk. The scenes are different and real, although it's virtual. On the whole, it's very good (GSUF05 Beizer).

Avatar: I have a unique avatar and others have theirs. And I can change my avatar as I want to. People can make friends 
with avatar's image here; it's really good and makes me happy (GSUF03 Baran).

Actions: There are so many actions and functions, including fly and teleport, which cannot be realized in real life. There, I can change clothes, do lots of actions, and make a variety of sounds, which can really enrich our talk (GSUM01 Biler).

Communications: It looks like a vivid English-corner. The atmosphere is active and real. In classroom learning, we don't have much chance to talk, while here, partners are warm-hearted, and talkative. I enjoy the feelings of communication here. (GSUM02 Migden).

General Feelings: SL is a virtual world. It's something like a virtual game since people can change images and doing actions in it. However, it isn't just a game but a medium of learning with the combination of a learning element and game element.... People can learn with fun and enjoy pleasure from learning, which improves our learning interests greatly (GSUF22 Altstatter).

Additionally, the EFL Program participants also completed 77 weekly blog postings commenting on their learning experiences in SL. Although the blog postings focused on describing the learning experiences in SL, the postings also portrayed their feelings toward SL as a language learning platform.

When I entered the virtual world, I was greatly shocked in that it was very vivid. There were many green trees, a beautiful lawn, and a big fountain. We were shown around the university.... I was deeply impressed. How fantastic it was! There was blue sea, clear sky and a lot of beautiful flowers. I liked it very much. My tour partner was GSUF27 Breiz. She enjoyed the virtual tour a lot too. We talked quite well, and we also walked around and flew together. It was terrific! We had a very good time, and both of us are now looking forward to the next tour (GSUF17 Beres).

I met my partner and took several pictures. I flew in the sky overseeing the objects on the ground. It was very interesting. My friends also like this kind of virtual life. It's a very good way to make friends online and it makes the process more interesting and they have more topics to talk about. We think that the project will do much good to our English study (GSUM03 Atlass).

To sum up, the Chinese students had positive feelings towards SL as an EFL learning platform and wished to use it for EFL learning more often in the future.

\subsection{The EFL Program in $S L$}

The participants' perceptions of the EFL Program in SL were also revealed through the post-program survey, interviews, and blog postings. Of the 23 survey items in the postprogram survey, 13 addressed the participants' perceptions of the EFL Program in SL, specifically the SL learning environment, communication, task partner, and their general feelings. The analysis of the post-program survey yielded positive results as indicated in Table 6.

The EFL Program participants perceived the EFL program to be generally interesting and positive (Mean $=4.18, S D=.76)$. They liked the SL learning environments and 
Table 6. Summary of the Post-program Survey Results on the EFL Program in SL

EFL Program participants at the Chinese university $(n=20)$

\begin{tabular}{lccc}
\hline \multicolumn{1}{c}{ Survey Categories } & No. of Survey Items & Mean & $S D$ \\
\hline Learning Environment & 3 & 4.08 & .77 \\
Communications & 3 & 4.25 & .85 \\
Task partners & 4 & 4.30 & .72 \\
General Feelings & 3 & 4.10 & .82 \\
\hline Overall & 13 & 4.18 & .76 \\
\hline
\end{tabular}

communications in SL. They enjoyed working with their task partners as avatars in SL. The interview analysis also supported the findings in the post-program survey.

SL Learning Environment: I feel relaxed and free in Second Life. And, I think that it can improve English learning a lot. I've been searching for this kind of environment since I entered this college, because when you speak English in a campus or dormitory, other students may regard you as a crank. But here, I don't need to worry about losing face, since partners cannot see my face (GSUF02 Baran).

Communications: This kind of communication is efficient and better. We can talk with an avatar, not face to face. In this way, we can talk without anxiety. I like the teamwork form of communication. It's new and interesting (GSUF03 Baran).

Task partners: The American students were patient and supportive. When they talked with me, they deliberately slowed down their speech a bit. When I was nervous, they always encouraged me by saying that I was excellent. When the communication dropped, they tried to think of something to say. I feel lucky to talk with them (GSUF22 Altstatter).

General Feelings: This is a convenient, practical, and reliable learning platform. We can learn many things while staying in the dormitory. Meanwhile, we can learn a lot of things which cannot be learned in the textbooks. It's real English and everyday English. Leaning by talking with other English speaking people would let me learn more (GSUM08 Kass).

The appreciation of the EFL Program in SL was also exhibited in their blog postings. Many of the EFL Program participants indicated that the learning tasks they completed with American partners were interesting and their communications with them in SL were of unforgettable learning experiences. The impact of this interaction was more than language learning as described by the following blog postings.

I really enjoyed talking with him, because he is so kind, humorous, and patient. To my surprise, we share lots of similarities. We became good friends the moment we started discussing. I'm 
very thankful to him for encouraging me to speak which increased my confidence in speaking English (GSUF02 Baran).

Personally, I use Xiaonei.com and QQ to talk with my friends. I also use email to communicate with others.... Obviously, they have more advanced technology which we haven't heard of before. She (GSU partner) uses Facebook and MSN while I use Xiaonei.com and QQ. But we both use email. That's wonderful. I learned a lot in the discussion. I'm really happy to talk with Ashley. I'm looking forward to another talk (GSUF27 Breiz).

\subsection{Perceived Problems}

The participants also perceived some problems as documented in their blog postings and through their interviews. Technical problems reported included poor audio quality during the chats (e.g., echoing and interrupted flow of audio sounds) and frozen screens. Both problems seriously impeded smooth communication and task completion in SL. Students also identified class management problems. Some American participants were late to be online at the given time and location in SL to work with the Chinese participants. After waiting for a short while, the Chinese participants who were so anxious to use every minute in SL for EFL learning would go to talk with other participants in other SL locations. As a result, the American participants could not find their Chinese counterparts when they got into SL. In addition to the problems mentioned above, the EFL Program participants also mentioned distracting objects in the SL learning environment in their interviews. These were the problems perceived by the EFL program participants and the problems that need to be dealt with when implementing the similar EFL programs in the future.

\subsection{Summary}

For perceived technology readiness, despite variances in online activities, the Chinese students were ready to use SL for EFL learning. The EFL Program participants perceived SL as a useful and interesting language learning platform. In addition, the EFL Program participants perceived the EFL Program in SL to be interesting and successful. With the problems observed and perceived, all the EFL Program participants liked the program and indicated that they would like to have more learning opportunities in SL in their future study.

Some limitations of the study need to be mentioned. Due to practical constraints, the study was conducted among a fairly small group of target students. Both the pre-program and post-program surveys were in English and some participants had difficulties in understanding some of the terms used in the surveys accurately as they indicated in both in the surveys and in the interviews. As a suggestion, formatting the survey in Chinese will help enhance the validity and reliability of the surveys, and hence, their results. With these limitations, we want to remind the readers of the extent to which the study's results and conclusions can be generalized.

\section{Discussion}

Because the overall purpose of the research collaboration was to find appropriate and innovative ways to integrate SL into an EFL program in Chinese universities, the discussion focuses on the implications drawn for integrating SL into the future EFL Program in China. 


\subsection{Designing EFL Programs in SL}

Technology readiness is a crucial factor that contributes to the success of any technology enriched learning programs. Lim, Nonis, and Hedberg (2006) explored ways in which a MUVE, known as "Quest Atlantis," was used in science lessons to support eight elementary students' learning in Singapore. They found that lack of computer competency was one of the factors that contributed to a low level of engagement of the students in virtual inquiry activities. However, the Chinese students were technologically ready to use SL for EFL learning according to the findings in this study. After a relatively short training session, they were capable of completing more sophisticated tasks than just chatting with avatars in SL.

Because the Chinese students were technologically ready to SL for EFL learning, it is suggested that the future EFL programs use a wide array of tasks including those that are sophisticated to perform in SL. In other words, the future EFL programs should use not only learning tasks that elicit structured interactions (e.g., interviewing native speakers), but also those that elicit semi-structured or improvised interactions (e.g., virtual field trips to historically significant places, visits to virtual museums, organizing and participating in virtual conferences, designing and constructing cultural centers, creating virtual art shows and so on). According to Vygotsky (1978), interactions promote learning. Meaningful and authentic interactions of those tasks in SL would equip the EFL students with knowledge about English speaking cultures and provide them with appropriate ways of expressing themselves in social circumstances.

The Chinese students liked SL and the EFL Program in SL in general. However, the perceived problems with the SL learning environment should not be ignored. With regard to designing future EFL programs in SL, both physical and virtual learning environmental elements need to be carefully considered. Physical world constraints such as Web access and students' physical surroundings affect students' online experience. For example, computer stations need to be equipped with large amounts of RAM, high end graphic cards, and fast processors as the activities in SL using text, audio, and video communications require extensive computing resources. Also, a large group of students being together in one location both physically and virtually in SL creates echoing effects with audio communication which hinder student interactions in SL.

Selecting virtual environments needs to be equally, carefully considered. There are many objects in SL that could interfere and distract students when attempting to complete given tasks. For example, it may not be appropriate to select a seashore site in SL where, among other things, several dolphins regularly jump out of the sea when the students need to concentrate on their discussion that are not related to dolphins.

\subsection{Facilitating EFL Learning in $S L$}

The following is suggested to facilitate students' language performance and scaffold their language learning in SL.

Prepare students for task completion. Prior to engaging learners in SL tasks, preparing them in the target language is important. The task preparation includes both language and necessary cultural and background knowledge needed for particular social interactions in SL. Task preparation increases students' confidence in task completion, and as a result, makes better use of SL for language learning.

Set a time limit for any given task. Because the interactions in SL require participants to 
be present at the same time and in the same location in SL, managing a class in SL is more difficult than that in face-to-face ones. Scholars (Ellis, 2003; Lee, 2000) have long recognized time as an important factor in student language performance. To help students become more efficient in their task completion, instructors should inform students of the time for task completion and set a time limit for any given task in SL, especially when it involves participants across time zones.

Closely monitor student language performance. Instructors need to closely monitor students' language performance in SL. The instructor's presence helps students avoid "just another game" mentality when they use SL for EFL learning. There also may be unexpected distractions and interruptions such as uninvited avatars flying around or falling down right in front of the student avatars that may be easier to overcome with the instructor's participation.

Encourage post-task reflection. Ellis (2003) examined interrelated research on task-based language learning and instruction and found that post-task reflection is an important part of the task-based learning process. Post-task reflection can be done in different formats. Some common post-reflection activities include (a) individual student reports on task completion (oral or written), (b) group discussions on task completion, or (c) watching student SL video clips in class and then having students comment on their language performance. The focus of post-task reflection can vary. We believe that having students watch their own language performance recorded in SL would help their reflection and be beneficial to their language learning experience.

Provide feedback. Feedback, a communication procedure that informs the students of their language performance against given instructional objectives or academic standards, has been an important component of learning and instruction (Gagné, 1985; Jonassen, 1991; Mory, 1996). According to Mory (1996), feedback can include a wide array of information from answer correctness and language uses to motivation messages. The Chinese EFL students expressed that they wanted feedback on their language performance from both their Chinese facilitators and their American counterparts. Feedback should include both encouragement and error correction.

\section{Conclusion}

This paper reported Chinese students' perspectives on using Second Life for EFL learning. Specifically, the paper reported the Chinese students' perceived technology readiness to use SL for EFL learning, their perceptions of SL, and the EFL Program implemented in SL at the Chinese university. Our work was grounded on constructivist learning perspectives and attempted to draw upon the affordances that SL could offer to this context. Based on the study results, we discussed the implications and made a set of recommendations for designing and implementing similar EFL programs. The rapid evolution of digital media has afforded us the opportunity to assimilate new technologies while exploring new pedagogies in EFL language learning. We believe that the work described here has barely touched upon this potential and we are excited about what the future may bring.

\section{References}

$\mathrm{Au}, \mathrm{W}$. J. (2008). The making of Second Life: Notes from the new world. NY: Harper Collins Publisher.

Belcher, D. \& Hirvela, A. (Eds.). (2008). The oral-literate connection: Perspectives on 
L2 speaking, writing, and other media interactions. Ann Arbor, MI: University of Michigan Press.

Black, R. W. (2005). Access and affiliation: The literacy and composition practices of English language learners in an online fanfiction community. Journal of Adolescent and Adult Literacy, 49(2), 118-128.

Cochran-Smith, M., \& Donnell, K. (2006). Practitioner inquiry: Blurring the boundaries of research and practice. In J. L. Green, G. Camilli, P. B. Elmore \& A. E. R. Association. (Eds.), Handbook of complementary methods in education research. Mahwah, NJ: Lawrence Erlbaum Associates.

Cooke-Plagwitz, J. (2008). New directions in CALL: An objective introduction to Second Life. CALICO Journal, 25(3), 547-557.

Creswell, J. W. (2008). Educational research: Planning, conducting, and evaluating quantitative and qualitative research (3rd ed.). Upper Saddle River, NJ: Pearson Education Inc.

Driscoll, M. P. (2000). Psychology of learning for instruction. Boston, MA: Allyn and Bacon.

Ellis, R. (2003). Task-based language learning and teaching. Cambridge: Oxford University Press.

Gagné, R. M. (1985). The conditions of learning (4th ed.). New York: CBS College.

Jonassen, D. H. (1991). Objectivism versus constructivism: Do we need a new philosophical paradigm? Educational Technology Research and Development, 39(3), 5-14.

Kelton, A. J. (2007). Second Life: Reaching into the virtual world of real-world learning. EDUCAUSE Center for Applied Research, Research Bulletin (August 2007, Issue 17). Retrieved September 12, 2009, from http:// net.educause.edu/ir/library/pdf/ERB0717. pdf

Krathwohl,D.R.(1998).Methodsofeducational and social science research (2nd ed.). New York: Addison Wesley Longman, Inc.

Lam, E. W. S. (2000). L2 literacy and the design of the self: A case study of a teenager writing on the internet. TESOL Quarterly, $34(3), 457-481$.

Lamb, G. L. (2006). At colleges, real learning in a virtual world. Christian Science Monitor. Retrieved September 10, 2009, from http:// www.usatoday.com/tech/gaming/2006-1005-second-life-class_x.htm

Lee, J. (2000). Tasks and communicating in language classrooms. Boston, MA: McGraw-Hill.

Li, Z. \& Mao, Y. (2008). Second life教育潜能 研究及其对远程教育的启示 (The study of educational potentials of Second Life and its implications to distance education) 现代教育技术 (Modern Educational Technology), 18(1), 81-83.

Lim, C., Nonis, D., \& Hedberg, J. (2006). Gaming in a 3D multiuser virtual environment: Engaging students in science lessons. British Journal of Educational Technology, 37(2), 211-231.

McMillan, J. H., \& Schumacher, S. (1997). Research in education: A conceptual introduction (4th ed.). New York: Longman, Inc.

Mory, E. H. (1996). Feedback research. In D. H. Jonassen (Ed.), Handbook of research for educational communications and technologies. New York: Simon \& Schuster MacMillan.

Nelson, B., \& Ketelhut, D.J. (2007). Scientific inquiry in educational multi-user virtual environments. Educational Psychology Review, 19(3), 265-283.

Second Life Economic Statistics. Retrieved August 28, 2009, from http://www. secondlife.com/

Shei, C. (2005). Integrating content learning and ESL writing in a translation commentary writing aid. Computer Assisted Language Learning, 18(1-2), 33-48. 
Vygotsky, L. (1978). Interaction between learning and development. In M. Gauvain \& M. Cole (Eds.), Readings on the Development of Children (pp. 34-40). New York: Scientific American Books.

Yi, Y. (2008). Relay writing in an adolescent online community. Journal of Adolescent \& Adult Literacy, 51(8), 670-680.

\section{Acknowledgements}

Authors of this article want to thank Associate Professor Shuzhuang Hao and Professor Li Yin at Yantai University and Patricia Early, Kathryn Land, Dave Stone, Shuxiang Sun and Qi Wang at Georgia State University for their important support to the EFL research program in SL.

\section{Contact the Authors}

Charles Xiaoxue Wang, Ph.D. Georgia State University, USA E-mail: xwang10@gsu.edu

\section{Hongbo Song, Ph.D.}

Yantai University, P. R. China

E-mail: hongbo_song@hotmail.com

\section{Fangli Xia}

Yantai University, P. R. China

E-mail: xiafangli1976@yahoo.com.cn

\section{Qiaoqiao Yan}

Yantai University, P. R. China

E-mail: cathyyqq1983@163.com 